\title{
Hospitalization Event
}

National Cancer Institute

\section{Source}

National Cancer Institute. Hospitalization Event. NCI Thesaurus. Code C80481.

The description of an event that occurred in an individual during the hospitalization period. 